\title{
Relationship between Tire Ground Characteristics and Vibration Noise
}

\author{
Haichao Zhou $1{ }^{1}{ }^{*}-$ Huiyun Li ${ }^{1}$ - Chen Liang1 - Lingxin Zhang ${ }^{2}$ - Guolin Wang1 \\ 1 Jiangsu University, School of Automotive and Traffic Engineering, China \\ 2 AEOLUS Tyre Co. Ltd, China
}

To study the relationship between tire ground characteristic parameters and vibration noise, a radial truck tire (295/80R22.5) is selected as the research object, and a finite element model is established. The test results of the tire stiffness, vibration modal, and surface velocity response are used to verify the model. In order to find the influence of the inherent vibration characteristics of a tire on radiated noise, the contour design and belt design are selected as design schemes, and a modal analysis and vibration noise numerical simulation analysis are carried out for different tire structures. The footprints of the tire-ground are refined and divided. All the grounding parameters of each subarea are extracted, and the relationships between the geometric and mechanical parameters of the tire ground characteristics and vibration noise are investigated. Then, the effects of the skewness and stiffness of tread deformation, as well as the spectral density of tire-road excitation force power on vibration noise, are analysed. The results showed that a positive correlation exists between the vibration noise and the skewness of the tread radial deformation; however, a negative correlation is observed between the vibration noise and radial deformation stiffness. The peak values and numbers of the tire excitation force power spectral density using the minimum noise structure design are significantly smaller than those of the original tire. This study can serve as a theoretical guideline for the structural design of low-noise tires. Keywords: tire noise, ground characteristic parameters, numerical simulation, modal analysis, tread stiffness, power spectral density

Highlights

- $\quad$ Tire dynamic model is established and validated, and tire vibration noise model is introduced.

- $\quad$ The effects of tire contour profiles and belt structures on vibration noise are compared and analysed, and the geometric and mechanical parameters of tire ground characteristics are introduced.

- $\quad$ Relationships between tire ground characteristics and tire vibration noise are established.

- $\quad$ The mechanisms of the reduction of tire vibration noise are analysed based on the tread radial deformations and excitation force power spectral density.

\section{O INTRODUCTION}

Noise pollution produced by vehicles is a prominent issue in modern society, especially for the inhabitants of urban areas. Studies have shown that road traffic noise is a remarkably complex phenomenon, with different sources such as the power unit, aerodynamics, and tire-road interaction [1] and [2]. According to statistics, when heavy trucks travel at speeds of more than $70 \mathrm{~km} / \mathrm{h}$, tire noise becomes the main source of noise of a vehicle [3]. A combination of vibrodynamic and aerodynamic phenomena occurs during the generation of tire noise, when the tire and road come into contact. The vibration noise originating from vibrodynamic phenomena has a frequency lower than $1 \mathrm{kHz}$ and is due to tire vibrations arising from the contact of the tires with irregularities in the road surface [4]. To reduce tire noise, the European Union, the United States, Japan, and China have passed laws and regulations, with clear requirements and implementation periods for improvements to noise performance. Therefore, the development of low- noise tires is of practical significance and has value as an engineering guideline.

The main source of noise in truck and bus radial (TBR) tires is structural vibration [5] and [6]. The vibration of a tire is mainly caused by the external and internal excitation of the tire. Dubois et al. [7] used a flat plate and thin shell model to simplify a tire and obtain the excitation force of it when it rolls on a road surface, and they calculated the vibration noise under this exciting force. Belgacem et al. [6] noted that the vibration noise of a tire can be predicted by using the Helmholtz equation and that reducing the tire excitation force can reduce tire vibration noise. Zhou et al. [8] studied the influence of the belt structure on tire vibration and noise; they found that optimizing the belt helped reduce the acceleration peak of the tread and sidewall and decrease the tire noise. Wang et al. [9] researched the effects of the tread design parameters on tire vibration noise and found that the tread is the main acoustic component that contributes to tire noise.

Tires are the only parts of a vehicle that come into contact with the road surface, and therefore, tire 
ground characteristics are the integrative reflections of tire performance, including roll resistance, tire noise, tire wear, and hydroplaning [10] and [11]. Tire ground characteristics have a direct and considerable impact on tire properties, but the extent of the influence of different parameters on tire performances is different. Analysing tire ground characteristics helps to understand the interaction between tire and road, which is beneficial to tire structure design and pavement development [12]. Tire ground characteristics can be divided into the geometric parameters and mechanical parameters, and these parameters greatly influence contact pressure and grip performance [13]. Wang et al. [14] controlled the tread deformation to decrease stress concentration and increase contact pressure uniformity, which resulted in the improvement of tire grip. Liang [15] explored the effects of tire contour shape on tire noise and found that the contour structure reduces tire noise owing to its effect on tire contact pressure distribution. Hubbell [16] proposed that the ground shape factor be chosen to evaluate the tire noise level in the footprint and concluded that tire vibration noise changes with the ground shape factor changes. Cesbron et al. [17] studied the relationship between ground pressure distribution of a radial tire and the outdoor noise test, it is found that the two properties between $500 \mathrm{~Hz}$ and $1000 \mathrm{~Hz}$ had a strong correlation. Cohn [18] used different inflation pressure to analyse tire ground and roll resistance, demonstrating an obvious correlation between them.

As mentioned above, the previous studies have mainly focused on tire noise analysis or the effects of structural design, and have analysed the relationship between tire noise and tire-road surface. However, in-depth studies on the relationships between the vibration noise and ground characteristic parameters have not been conducted.

Therefore, the aim of this study is to investigate the effects of the structural parameters of a tire on tire noise and ground characteristic parameters and establish a relationship between tire noise and ground characteristics. A series of tire structures schemes, including tire contour profiles and belt plies, are designed using the orthogonal experimental design method. Additionally, the noise characteristics and ground characteristics of tires of different structures are analysed. Finally, the tread deformation skewness and stiffness are compared, and the power spectral density of the tire radial excitation force of the minimum noise design is compared with that of the original design. This research aims to improve efficiency in the design of low-noise tires.

\section{TIRE MODEL ESTABLISH AND VIBRATION NOISE ANALYSIS}

\subsection{Tire Modelling and Verification}

A three-dimensional finite element model of the radial truck tire $(295 / 80 \mathrm{R} 22.5)$ is established under the inflation pressure $900 \mathrm{kPa}$, with a load of 35,500 $\mathrm{N}$, as shown in Fig. 1. The rubber is an isotropic hyper-elastic material and can be described by the Yeoh model. The steel cord is considered an isotropic material. The cord-rubber composite is modelled with rebar layers, such as belts and carcasses. The rim and road are defined as analytical rigid bodies, and the tire loading process is implemented by moving the road surface to a special position until a given force is attained. To verify the validity of the finite element model, measuring of the tire stiffness in three directions is carried out by using the MTM-2 tire testing machine. The details on the simulation method and testing process are presented in [19]. Fig. 2 shows a comparison of the three different load-deflection characteristics between simulation and test. It can be seen that the simulation results are in good agreement with the test data.

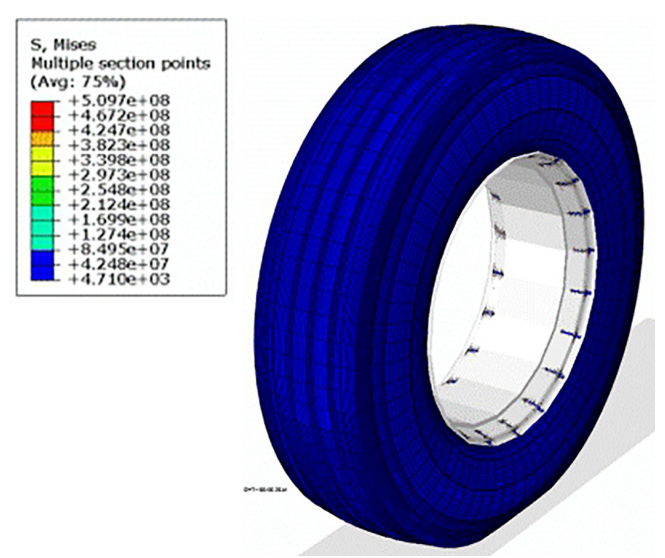

Fig. 1. Three-dimensional finite element model of tire

The dynamic characteristics of a tire have a considerable impact on tire vibration noise. Therefore, a dynamic signal analyser is used to measure the vibration modal characteristics of the tire, as shown in Fig. 3. Because that there are 81 vibration response points on the tread, the free model characteristics of the tire are obtained only in the radial direction. In Abaqus software, the Block Lanczos method is used to calculate the natural frequency. Table 1 presents a comparison between the measured and predicted tire modal frequencies; it can be seen that there is a good agreement between the measured and predicted 
Table 1. Comparison of radial modal characteristics between simulated and tested

\begin{tabular}{lcccccc}
\hline Radial order & 1 & 2 & 3 & 4 & 5 & 6 \\
\hline Test result [Hz] & 83.63 & 94.63 & 113.18 & 132.48 & 153.12 & 173.97 \\
\hline Simulation result [Hz] & 81.78 & 91.57 & 109.75 & 128.9 & 149.08 & 169.6 \\
\hline Error [\%] & -2.21 & -3. & $-3.03 \%$ & -2.70 & -2.64 & -2.51 \\
\hline
\end{tabular}

natural frequencies of the former six modals, with a maximum error of $3.2 \%$.

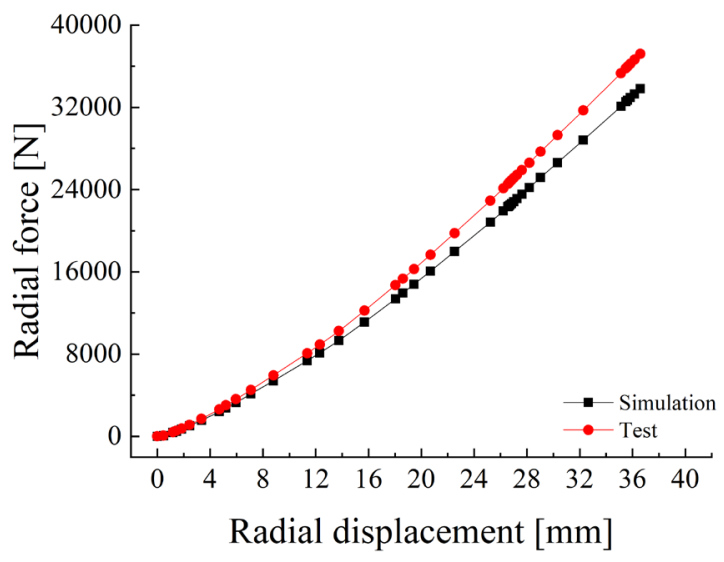

a)

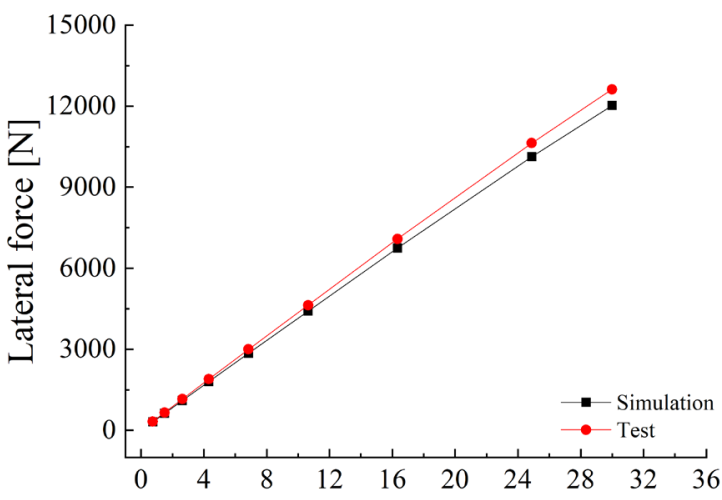

b)

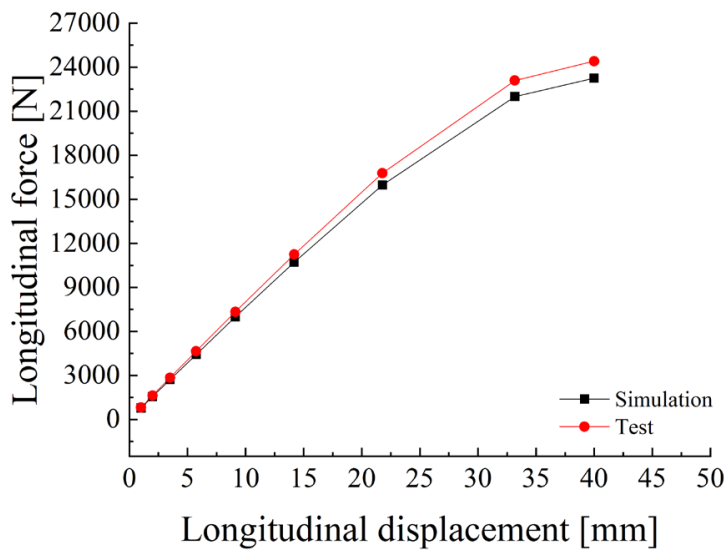

Fig. 2. Comparison of tire load-deflection characteristics between simulation and measurement; a) radial; b) lateral; and c) longitudinal forces and displacements
According to boundary element theory, the characteristic of the vibration response of a rolling tire is the main source of tire vibration noise [20]. Because of limitations in the dimensions that of the tire drum tester, the surface vibration response of a 215/75R 17.5 tire is selected for testing. The simulation and test results are then compared to validate the tire dynamic model established in this study. The tire is loaded on the tire drum test machine, as shown in Fig. 4. During the test, the tire load is $10,000 \mathrm{~N}$, the air pressure is $830 \mathrm{kPa}$, and the rolling speed is $30 \mathrm{~km} / \mathrm{h}$. A Polytec single-point laser Doppler vibrometer is used to measure the vibration of the tire sidewall. The test time and sampling frequency are $1.28 \mathrm{~s}$ and $1024 \mathrm{~Hz}$, respectively.

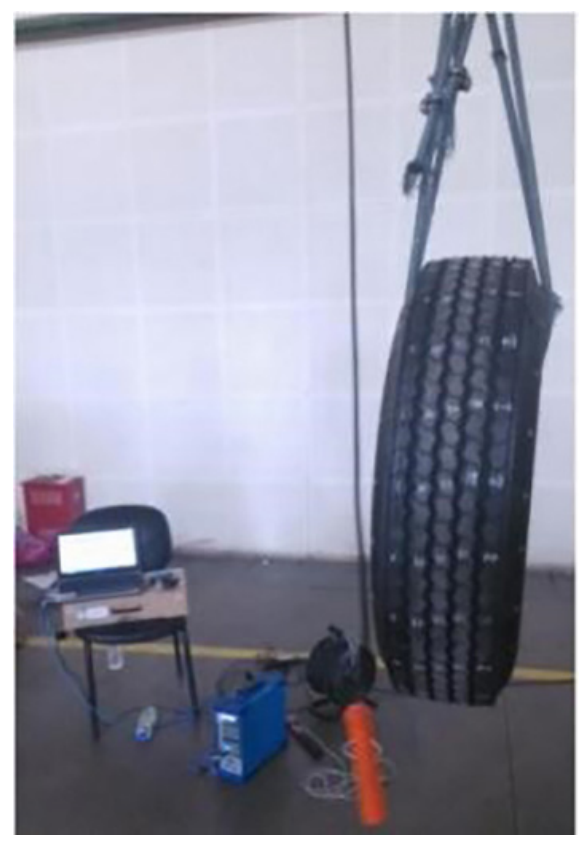

Fig. 3. Overview of tire modal test

During the test, the laser Doppler vibrometer is fixed on a tripod and connected to a computer through a data collector, as shown in Fig. 4. The tripod is placed approximately $50 \mathrm{~cm}$ from the tire, and a laser beam is focused onto the sidewall measurement point, the focusing knob is turned, and the position of the tripod is adjusted for performing the measurement at different points. 
Abaqus/Explicit is used to simulate the rolling of the tire at $30 \mathrm{~km} / \mathrm{h}$. Four points on the sidewall of the rolling tire are measured to analyse the vibration characteristics of the sidewall, as shown in Fig. 4.
The positive direction of the $z$-axis is the direction towards the ground, and the angle of the measuring point is the angle between the straight line connected by the measuring point and the positive direction

a)
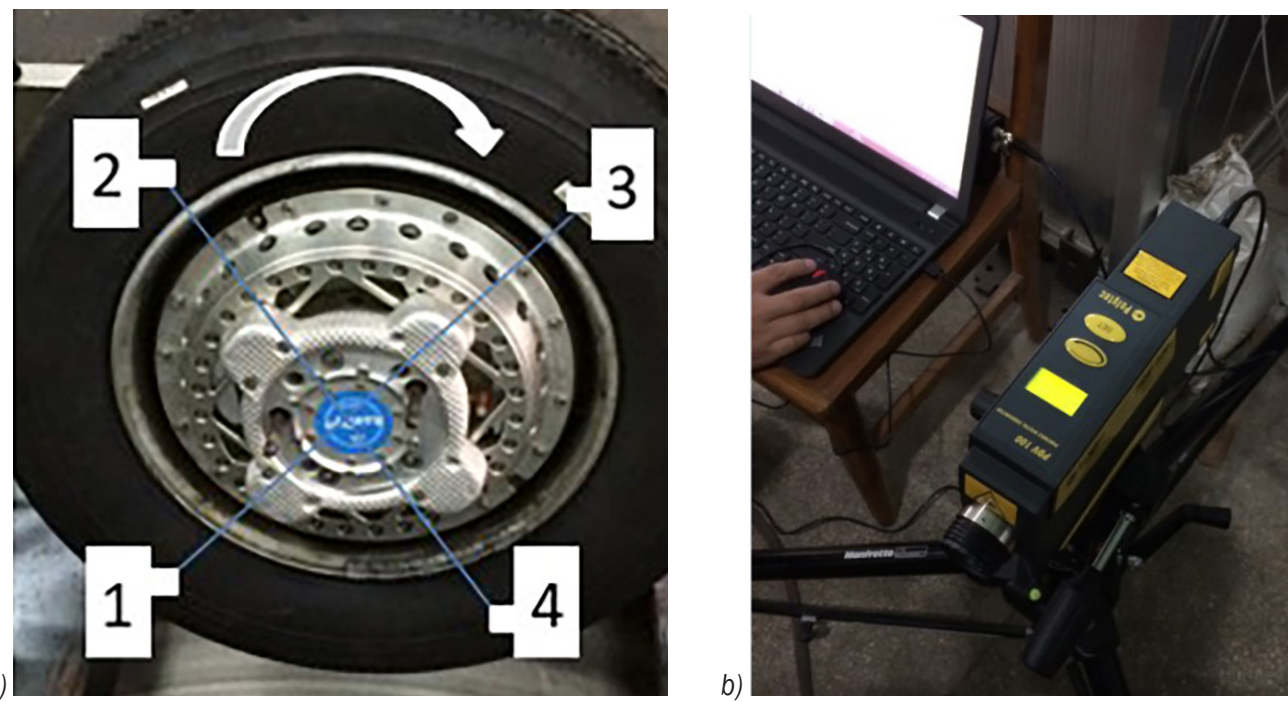

Fig. 4. Experiment to measure vibration response of the rolling tire;

a) placement of vibration measurement points for test tire; and b) laser Doppler vibrometer
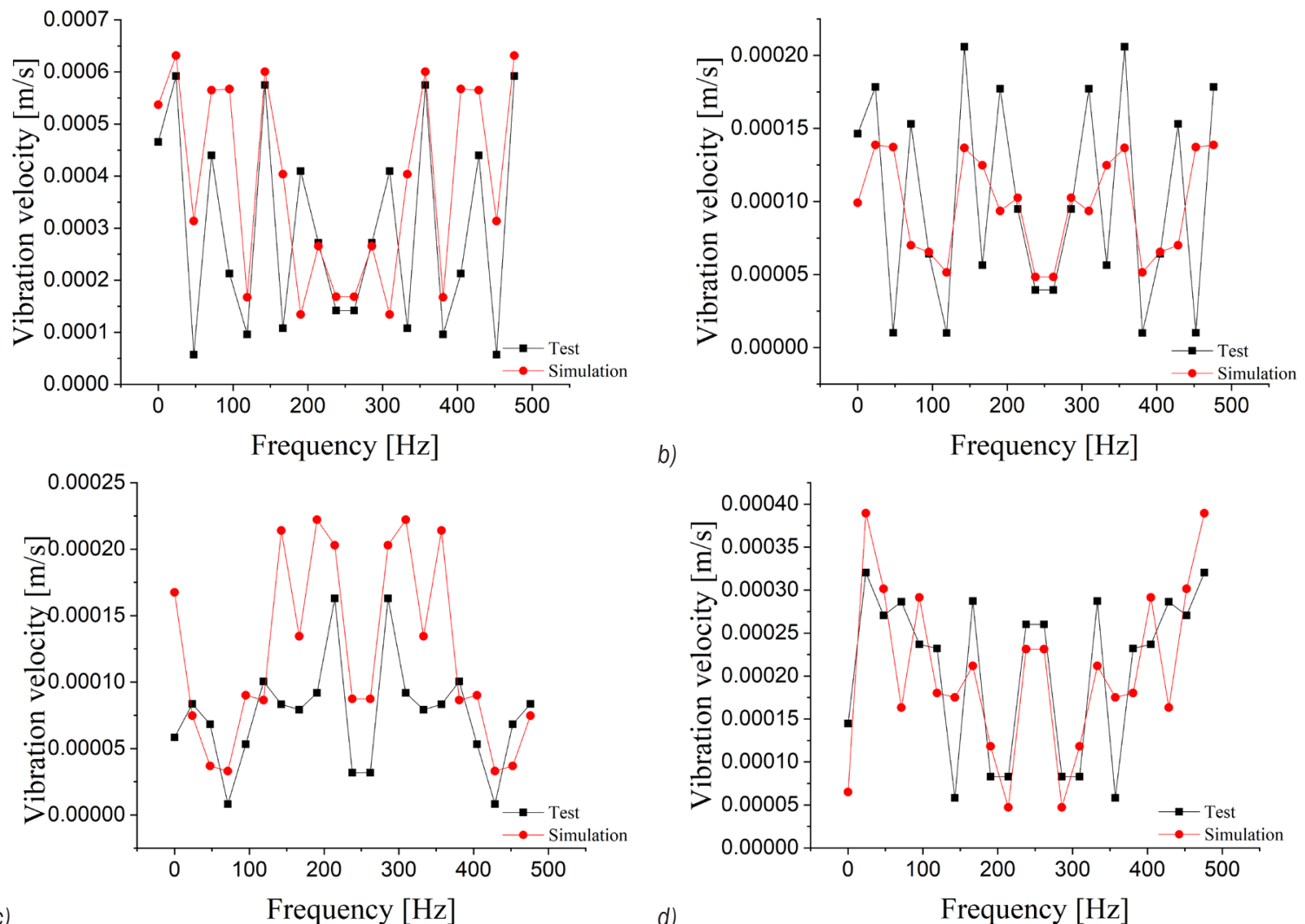

b)

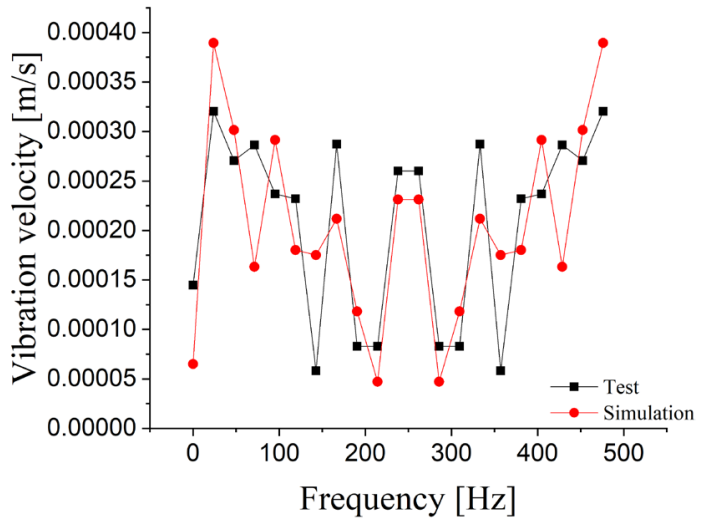

Fig. 5. Comparison of vibration responses between simulation and measurement in the frequency domain; comparison of test and simulation at measurement a) point 1; b) point 2; c) point 3; and d) point 4 
of the $z$-axis. The angles of the four measurement points were in the $x z$ coordinate plane are $45^{\circ}, 135^{\circ}$, $225^{\circ}$, and $315^{\circ}$ in the clockwise direction. The first measurement point is the grounding rear end, and the fourth measurement point is the grounding front end. In order to better compare the test results with the simulation results, the signal in the time domain is subjected to a discrete Fourier transform to obtain the vibration velocity curve in the frequency domain. The results are shown in Fig. 5. It can be seen that the distributions of the vibration velocity obtained in the simulation are in good agreement with those in the test.

\subsection{Numerical Analysis of Tire Vibration Noise}

A numerical analysis of the tire vibration noise is conducted using the boundary element method. A surface mesh used for noise simulation is extracted from the finite element model of the loaded tire presented Fig. 1. To avoid leakage of acoustic energy, the acoustic boundary element model is sealed by simply meshing the round edges in contact with the rim, as shown in Fig. 6.

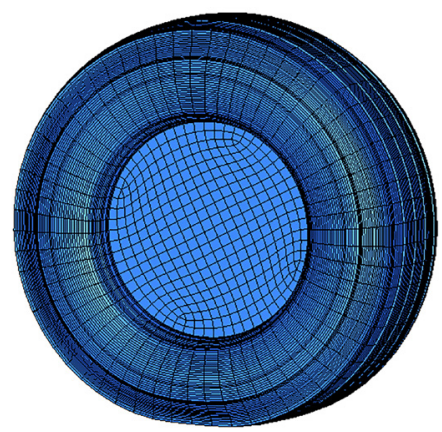

Fig. 6. Boundary element model of a tire

According to the GB/T3767-1999 standard, 19 observation points (OP) are distributed on a semisphere with a radius of $1 \mathrm{~m}$. The sound pressure level of tire vibration noise is the superposition of A-weighted sound levels from the 19 observation points. The acoustic analysis model and distribution of observation points are shown in Fig. 7. The road surface is treated as a rigid reflection surface.

In this study, the rolling of a tire is simulated using Abaqus/Explicit, and the radial force of the rim centre under steady-state rolling is extracted as the excitation force to carry out noise simulation. The change in the radial excitation force of rim centre over time is shown in Fig. 8.

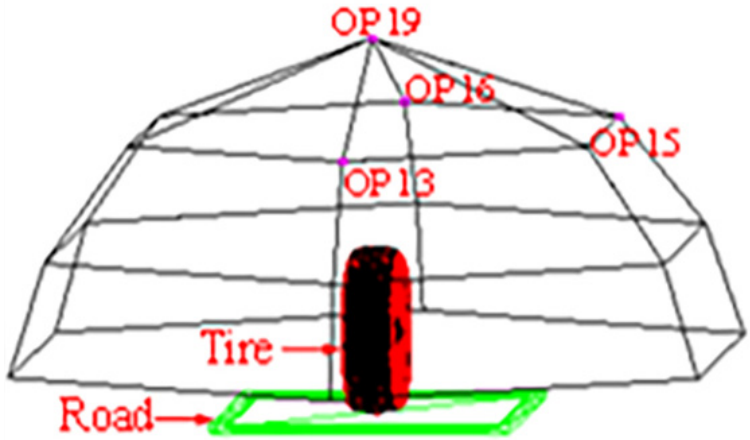

Fig. 7. Acoustic prediction model and acoustic pressure observation points $(O P)$

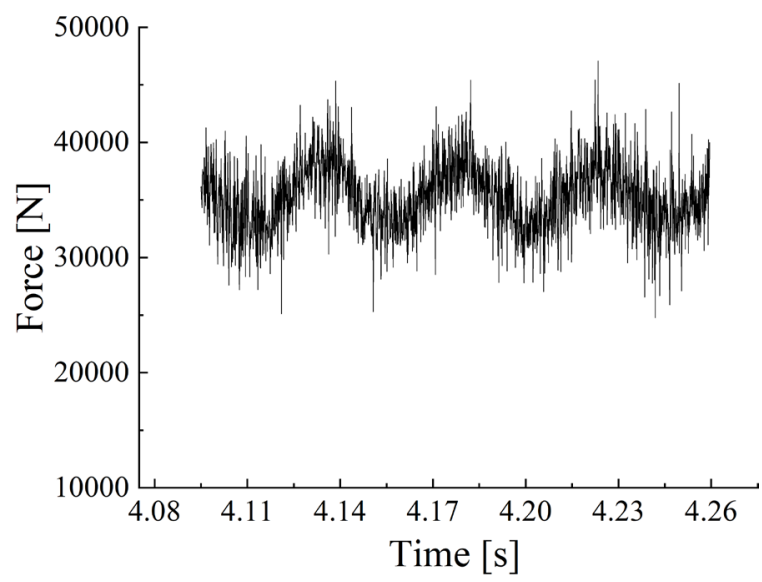

Fig. 8. Radial excitation force of the rim centre in time domain

A fast Fourier transform is applied to the radial excitation force in the time domain to derive the excitation force in the frequency domain, which is required to calculate the tire vibration noise, as shown in Fig. 9.

The excitation force of the rim centre in the frequency domain is imposed on the centre point of the tire ground contact patch. The results of the modal simulation are imported for calculating the modal participation factors. The LMS Virtual Lab acoustic software is used to simulate tire noise, the data at the nodes of the tire surface are transferred onto the acoustic mesh via data mapping, and the sound pressure value in the range $20 \mathrm{~Hz}$ to $500 \mathrm{~Hz}$ is computed using the modal acoustic transfer vector (MATV) method. The MATV method expresses the acoustic transfer function in modal coordinates from a radiating structure to a field point and, therefore, lists the acoustic contribution from each structural modal [21]. With the help of the MATV method, the structural modal matrix is multiplied for the modal coordinates under the LMS Virtual Lab acoustic software to compute noise. 


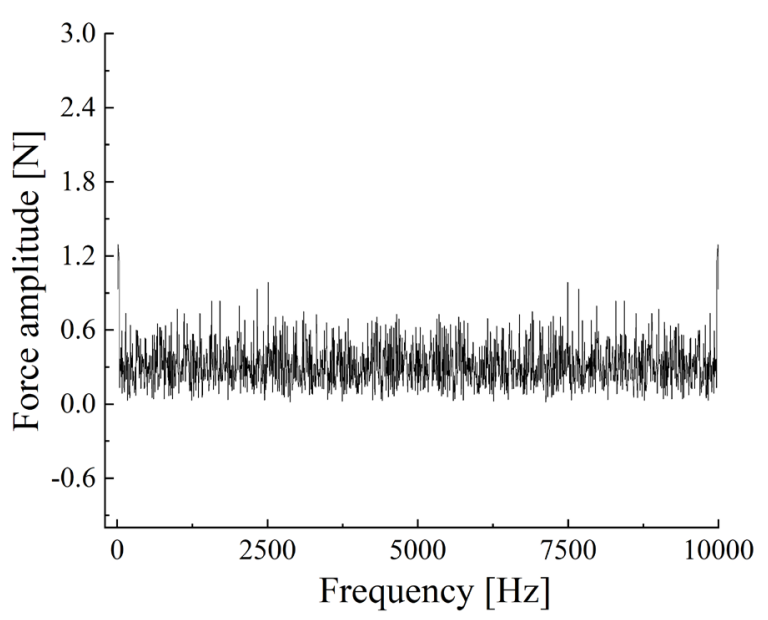

Fig. 9. Radial excitation force of the rim centre in frequency domain

After the selection of the observation points corresponding to the front end of the contact patch (OP13), the rear end (OP16), the top end (OP19), and the right sidewall (OP15), the distribution characteristics of vibration noise are shown in Fig. 10.

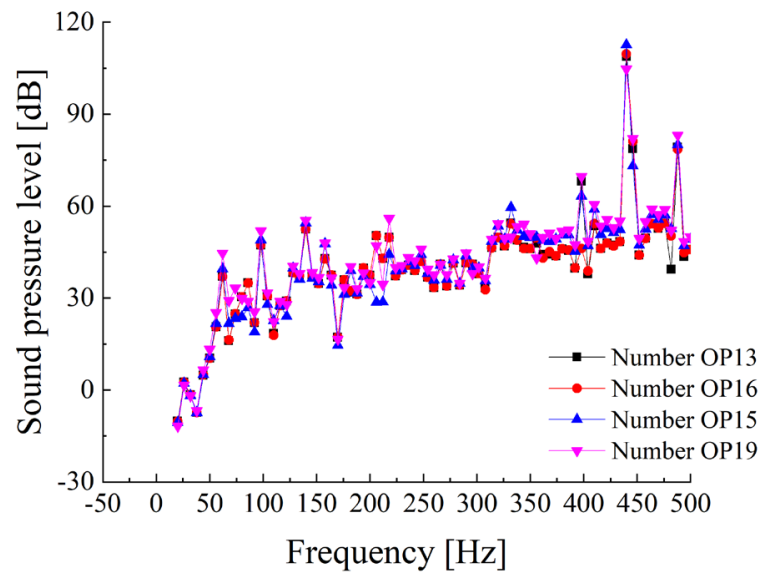

Fig. 10. Spectral curves of different acoustic observation points

Fig. 10 shows that the variation trends of the frequency-response function at different OPs are similar, whereas those of the sound pressures differ slightly. The peak noise values are mainly concentrated at $440 \mathrm{~Hz}$ and $488 \mathrm{~Hz}$. The sound pressure at the rear end of the contact patch (OP16) is higher than that at the front end of the contact patch (OP13), which is consistent with the results of experiments in [22] and [23].

\section{EFFECTS OF TIRE STRUCTURE DESIGN ON VIBRATION NOISE}

\subsection{New Non-Natural Equilibrium Contour Design}

The early tire contour design theory only considers the static characteristics of the tire; it does not consider the influence of tire manufacture factors on the tirebuilding process or the role of the strengthening layer and the belt on the inflation pressure. Therefore, the early tire contour design theory has some limitations in the modern structural design of the tire. More than 50 years after the tire contour design theory was proposed, Sakai proposed a theory for the non-natural equilibrium contour design of tires [24], and inspired Sakai's theory, a new non-natural equilibrium contour (NEC) design theory is proposed in this work, and the structure contour of a tire 295/80R22.5 is drawn using Matlab software, as shown in Fig. 11. The new non-natural equilibrium contour can effectively inhibit shoulder deformation, and increase the ground pressure distribution, and obtain a more reasonable contact shape [25].

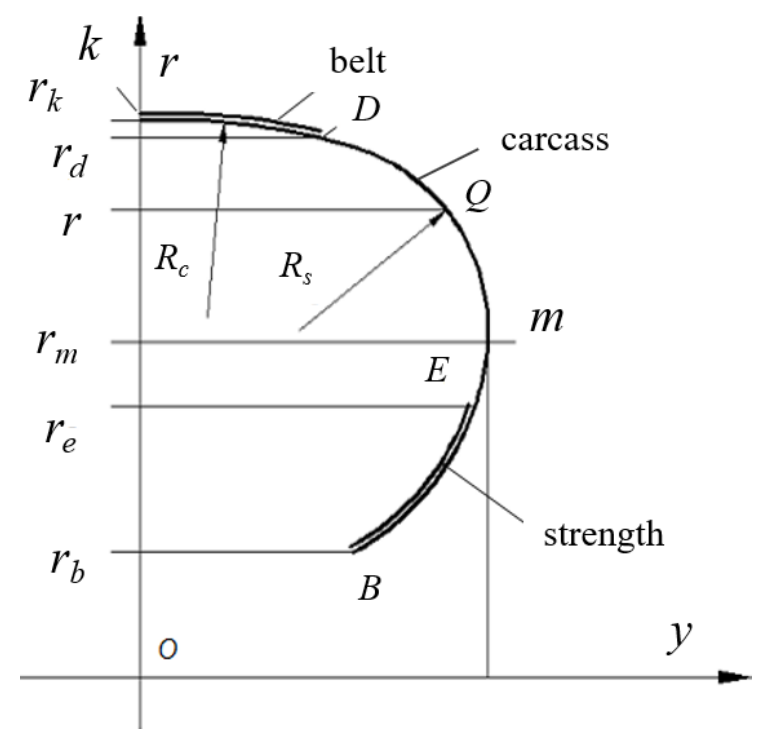

Fig. 11. Tire contour structure with belt layer and strength layer

In Fig. 11, $R_{c}$ is the curvature radius of the belt section, $R_{s}$ is the curvature radius of the carcass section, $r_{d}$ refers to the radius of the belt layer with respect to the axis of rotation, $r_{m}$ refers to the radius of the maximum width point with respect to the axis of rotation in the tire section, $\tau_{0}$ refers to the belt layer pressure rate, $r_{k}$ refers to the radius of the tire tread with respect to the axis of rotation, and $\alpha$ refers to the shape coefficient of the belt layer pressure rate. 
Variables $r_{d}, \tau_{0}, r_{k}$, and $\alpha$ are chosen as design variables that have a significant effect on the tire contour shape. Here, the orthogonal array (OA) is chosen to generate the design sample points [26]. The three levels of design variable $r_{d}$ are 483.13 $\mathrm{mm}, 485.13 \mathrm{~mm}$ and $487.13 \mathrm{~mm}$, the three levels of design variable $\tau_{0}$ are $0.7,0.8$ and 0.9 , the three levels of design variable $r_{k}$ are $491.94 \mathrm{~mm}, 493.94 \mathrm{~mm}$ and $495.94 \mathrm{~mm}$, the three levels of design variable $\alpha$ are 0.1, 0.2 and 0.3. According to the variables and levels, an OA table of $L_{9}\left(3^{4}\right)$ is generated. With the help of the analysis methods in Chapter 1, the modal frequencies and vibration noise of the different contour design schemes are listed in Table 2.

The range analysis can evaluate the influence of design variables on the sound pressure level (SPL), identify them as primary and secondary, and work out the optimal level combination of the design variables to obtain the most superior performance index from all the sample points. With the help of range analysis, the minimum noise value is obtained by optimizing tire contour design was $81.73 \mathrm{~dB}$.

Table 2. Former six-order natural frequencies and SPL of different NEC designs

\begin{tabular}{|c|c|c|c|c|c|c|c|}
\hline \multirow[b]{2}{*}{ No. } & \multicolumn{6}{|c|}{ Natural frequency [Hz] } & \multirow{2}{*}{$\begin{array}{r}\text { Noise } \\
{[\mathrm{dB}]}\end{array}$} \\
\hline & 1 & 2 & 3 & 4 & 5 & 6 & \\
\hline 1 & 60.81 & 82.26 & 98.46 & 114.18 & 129.29 & 142.75 & 82.95 \\
\hline 2 & 59.40 & 80.74 & 97.13 & 113.08 & 128.34 & 141.79 & 84.13 \\
\hline 3 & 57.84 & 78.93 & 95.42 & 111.61 & 127.14 & 140.72 & 95.91 \\
\hline 4 & 57.92 & 79.02 & 95.43 & 111.50 & 126.94 & 140.59 & 89.34 \\
\hline 5 & 58.15 & 79.62 & 96.23 & 112.29 & 127.64 & 141.25 & 83.64 \\
\hline 6 & 59.01 & 80.53 & 96.97 & 112.80 & 127.88 & 141.19 & 90.63 \\
\hline 7 & 56.75 & 78.04 & 94.67 & 110.81 & 126.25 & 139.94 & 94.24 \\
\hline 8 & 57.59 & 78.91 & 95.37 & 111.28 & 126.46 & 139.87 & 88.00 \\
\hline 9 & 58.44 & 79.86 & 96.21 & 111.95 & 126.98 & 140.41 & 86.60 \\
\hline
\end{tabular}

\subsection{Belt Structure Design}

The tire belt structure determines the bearing capacity and stiffness of the tire, and the tire contact pressure, distribution depends on the belt structural design [23]. The tire contact pressure distribution in turn affects the exciting force and consequently affects the vibration noise of the tire. Therefore, the relationship between ground characteristics and vibration noise can be studied by varying the structural design of the tire belt. The structural parameters of the belt include the thickness, width, and length of the belt; the angle of the cord; the density and arrangement; the number of plies; and the type and structure of the cord used. The tire 295/80R22.5 model consists of four belt layers (4-ply tire), but the main parts of the belt are the second and third layers when the tire is rolled. Therefore, taking the second belt layer and the third belt layer as the analysis objects in this work, the influence of the width and angle of the belt layers on the vibration noise are analysed by using the OA table of $L_{9}\left(3^{4}\right)$. In the orthogonal experiment, the three levels of the width of the second belt layer are 192 $\mathrm{mm}, 198 \mathrm{~mm}$ and $204 \mathrm{~mm}$, the three levels of the angle of the second belt layer are $12^{\circ}, 15^{\circ}$ and $18^{\circ}$; the three levels of the width of the third belt layer are 114 $\mathrm{mm}, 120 \mathrm{~mm}$ and $126 \mathrm{~mm}$, three levels of the angle of the third belt layer are $-12^{\circ},-15^{\circ}$ and $-18^{\circ}$. The former six-order modals frequencies and vibration noise of the different belt layer design schemes are listed in Table 3. With the help of the range analysis, the minimum noise value obtained by optimizing belt structure design is $84.22 \mathrm{~dB}$.

Table 3. Former six-order natural frequencies and SPL of different belt structure

\begin{tabular}{|c|c|c|c|c|c|c|c|}
\hline \multirow[b]{2}{*}{ No. } & \multicolumn{6}{|c|}{ Natural frequency $[\mathrm{Hz}]$} & \multirow{2}{*}{$\begin{array}{c}\text { Noise } \\
{[\mathrm{dB}]}\end{array}$} \\
\hline & 1 & 2 & 3 & 4 & 5 & 6 & \\
\hline 1 & 60.98 & 82.12 & 97.64 & 112.52 & 126.74 & 139.26 & 85.01 \\
\hline 2 & 61.02 & 82.16 & 97.71 & 112.56 & 126.71 & 139.21 & 87.63 \\
\hline 3 & 60.95 & 82.11 & 97.69 & 112.57 & 126.75 & 139.27 & 91.03 \\
\hline 4 & 60.92 & 82.02 & 97.53 & 112.39 & 126.63 & 139.35 & 89.30 \\
\hline 5 & 61.02 & 82.14 & 97.63 & 112.47 & 126.70 & 139.43 & 135.97 \\
\hline 6 & 60.88 & 82.00 & 97.55 & 112.45 & 126.72 & 139.42 & 95.52 \\
\hline 7 & 60.96 & 82.02 & 97.47 & 112.32 & 126.64 & 139.57 & 127.42 \\
\hline 8 & 60.90 & 81.98 & 97.45 & 112.30 & 126.61 & 139.49 & 121.59 \\
\hline 9 & 60.88 & 81.97 & 97.46 & 112.35 & 126.69 & 139.62 & 98.20 \\
\hline
\end{tabular}

\section{RESULT ANALYSES AND DISCUSSION}

\subsection{Relationship between Ground Parameters and Vibration Noise}

\subsubsection{Definition of Tire Ground Parameters}

The distribution characteristics of the tire ground pressure are evaluated using the Tire Footprint Analysis System (TFAS) software, which is a database analysis system that our team developed; the detail ground characteristics are shown in Fig. 12, and the detailed parameters description of the geometric and mechanical parameters of tire ground characteristics is presented in [15] and [27].

In Fig. 12, $\alpha_{1}, \alpha_{2}, \alpha_{3}$ and $\alpha_{4}$ are the four outer angles of the geometry shape of the tire contact with the ground, respectively. The shape coefficient of the tire-ground $F_{s r}$ represents the ratio of the sum of external angles of the footprint geometry to $360^{\circ} F_{s r}$ 

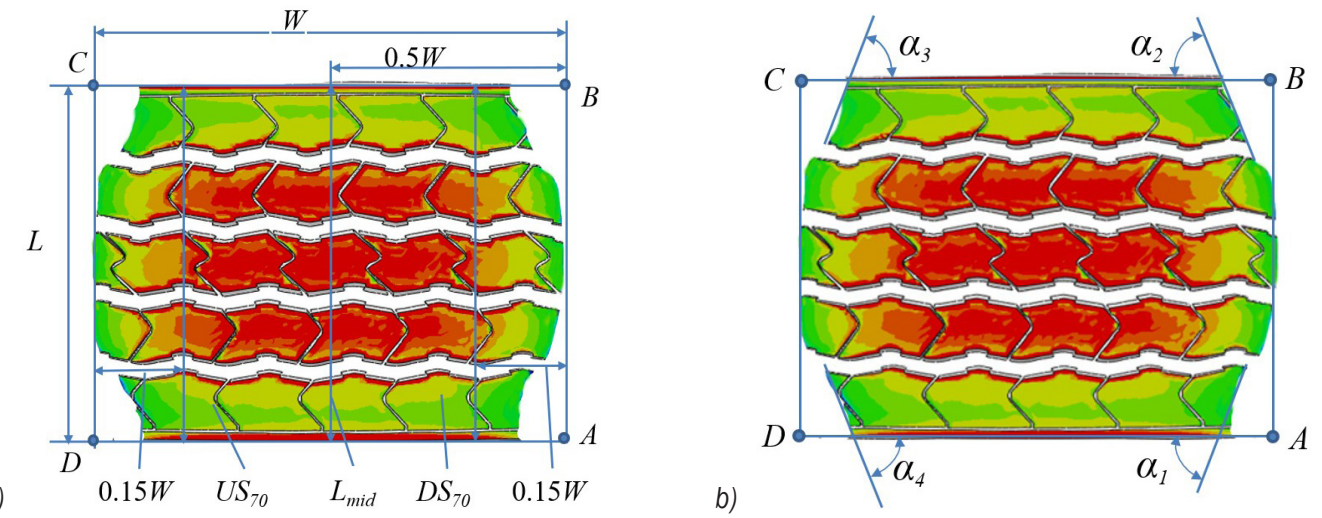

Fig. 12. Tire ground characteristics parameters; a) tire ground geometric parameters; and $b$ ) the four outer angles of the tire contact with the ground

can be calculated using Eq. (1). If $F_{s r}$ is higher than 1, the footprint shape is concave; if $F_{s r}$ is lower than 1, the footprint shape is convex; and if $F_{s r}$ is equal to 1 , the footprint shape is rectangular.

$$
F_{s r}=A / 360^{\circ}=\left(\alpha_{1}+\alpha_{2}+\alpha_{3}+\alpha_{4}\right) / 360^{\circ} .
$$

The $U S_{70}$ and $D S_{70}$ are the second-longest axis, their locations are 0.15 times the contact width $W$ nearby the edges. $L_{\text {mid }}$ is the third-longest axis in the middle of tire contact area. Then, the coefficient of the second-longest axis $D O F_{\text {avg }}$ and the coefficient of the third-longest axis $L F_{a v g}$ are obtained using Eq. (2). $A B$ and $C D$ are the lengths of the edges of the tire-ground in the lateral direction. $L$ is the maximum length of the tire-ground in the rolling direction, and $W$ is the maximum width of the tire-ground in the lateral direction. $\bar{P}$ is the average contact pressure in the tire-ground zone, which is obtained by dividing the load by the contact area.

$$
\left\{\begin{array}{l}
D O F_{\text {avg }}=0.5 \times\left(\frac{A B}{D S_{70}}+\frac{C D}{U S_{70}}\right) \\
L F_{\text {avg }}=0.5 \times\left(\frac{L_{\text {mid }}}{D S_{70}}+\frac{L_{\text {mid }}}{U S_{70}}\right)
\end{array} .\right.
$$

When the ratio of the tire height to width is greater than $60 \%$, the shape factor of the tire-ground proposed by the Goodyear Tire Company can be used to evaluate the noise level [16]. The shape factor characterizes the specific tire footprint configuration by using the relationship between the maximum length of the footprint in the rolling direction and the lengths of the first and second lateral edges at a fixed location in the tire width direction with a fixed location. It can be used to describe the potential noise level generated during the rotation of a tire contacting a road surface.
Inspired by the idea proposed by Goodyear, the ground shape factor $F S F_{70 \%}$ is selected to describe the potential noise level generated during the rotation of a tire contacting a road surface, as shown in Eq. (3):

$$
F S F_{70 \%}=\frac{L_{\text {mid }}}{U S_{70}+D S_{70}} .
$$

\subsubsection{Analysis of Ground Parameters}

Table 4 lists the tire ground parameters in each of the schemes of contour designs and belt structures. In the Table 4, the principle of the rowsis in accordance with the noise values, in other words, the first row corresponds to the lowest noise value, and the last row corresponds to the highest noise value.. The superscript number in Table 4 indicates the corresponding program number listed in Table 2 and Table 3. Taking the $\mathrm{NEC}^{1}$ as an example, it means the number 1 of NEC design.

The statistical analysis method is used to analyse the relationship between ground parameters and tire noise. Fig. 13 shows a scatter diagram of the relationship between the geometric and mechanical parameters of the tire ground and noise. It can draw a relationship from the figure as the followings:

1. The tire vibration noise will increase sharply under the contact area is larger than 49,000 $\mathrm{mm}^{2}$, which means that the contact area should be controlled within a reasonable range. If it exceeds a certain value, the noise will increase considerably.

2. As the third-longest axis and the third-longest axis coefficient $L F_{\text {avg }}$ increase, the vibration noise increases first and then decreases, and finally remains constant around $90 \mathrm{~dB}$. Accordingly, 
a suitable increase in the third-longest axis and the third-longest axis coefficients can reduce vibration noise. The reason for this may be that an increase in the third-longest axis could cause the shape of tire contact ground to become more rectangular, and this can reduce the contact pressure at the centre of the tread, and improve the uniformity of contact pressure; therefore, it is beneficial to reduce the vibration noise.

3. As the ground length and the coefficient of the second-longest axis $D O F_{\text {avg }}$ increase, the tire vibration noise first fluctuates smoothly and then quickly increased, especially the ground length and the second-longest axis coefficients are more than $192 \mathrm{~mm}$ and $0.88 \mathrm{~mm}$, respectively. Therefore, the ground length and the $D O F_{a v g}$ must be controlled within a reasonable range. Increasing ground length means that the contact pressure in the tread area would shift to the shoulder; if the shoulder stiffness is sufficiently large, the tread deformation will be transferred

Table 4. Tire ground characteristic parameters in each scheme

\begin{tabular}{|c|c|c|c|c|c|c|c|c|}
\hline & $C-A\left[\mathrm{~mm}^{2}\right]$ & $L_{\text {mid }}[\mathrm{mm}]$ & $D O F_{a v g}$ & $L F_{\text {avg }}$ & $F_{s r}$ & $U S_{70}[\mathrm{~mm}]$ & $D S_{70}[\mathrm{~mm}]$ & $A B$ [mm] \\
\hline NEC1 & 47920 & 246.35 & 0.86 & 1.13 & 0.81 & 218 & 218 & 188.49 \\
\hline NEC5 & 48764 & 248.45 & 0.83 & 1.17 & 0.73 & 213.14 & 213.14 & 176.39 \\
\hline $\mathrm{NEC}^{2}$ & 48638 & 246.56 & 0.84 & 1.16 & 0.74 & 213.42 & 213.42 & 178.89 \\
\hline Belt1 & 48985 & 242.21 & 0.88 & 1.11 & 0.78 & 217.89 & 217.89 & 192.23 \\
\hline NEC9 & 48544 & 244.2 & 0.85 & 1.14 & 0.75 & 213.65 & 213.64 & 181.82 \\
\hline Belt2 & 48917 & 241.35 & 0.88 & 1.11 & 0.78 & 216.97 & 216.97 & 191.59 \\
\hline NEC8 & 48766 & 246.01 & 0.83 & 1.16 & 0.73 & 212 & 212 & 176.6 \\
\hline Belt4 & 48979 & 241.36 & 0.88 & 1.11 & 0.78 & 216.74 & 216.74 & 191.11 \\
\hline NEC4 & 47721 & 248.24 & 0.84 & 1.16 & 0.77 & 214.3 & 214.3 & 178.97 \\
\hline NEC6 & 48989 & 245.4 & 0.86 & 1.14 & 0.76 & 215.5 & 215.49 & 184.37 \\
\hline Belt3 3 & 48530 & 242.7 & 0.87 & 1.13 & 0.76 & 214.86 & 214.85 & 185.87 \\
\hline NEC7 & 48776 & 249.03 & 0.82 & 1.18 & 0.71 & 211.84 & 211.83 & 173.12 \\
\hline Belt6 & 48678 & 243.58 & 0.86 & 1.13 & 0.76 & 215.45 & 215.45 & 186.16 \\
\hline $\mathrm{NEC}^{3}$ & 47004 & 250.22 & 0.81 & 1.19 & 0.73 & 210.8 & 210.8 & 169.77 \\
\hline Belt9 & 48629 & 242.9 & 0.87 & 1.13 & 0.76 & 251.12 & 251.12 & 186.19 \\
\hline Belt8 & 49271 & 242.9 & 0.88 & 1.11 & 0.79 & 218.24 & 218.24 & 192.58 \\
\hline Belt7 & 49333 & 242.94 & 0.88 & 1.11 & 0.79 & 217.98 & 217.98 & 191.99 \\
\hline \multirow[t]{2}{*}{ Belt5 } & 49249 & 242.12 & 0.88 & 1.11 & 0.79 & 217.75 & 217.75 & 192.38 \\
\hline & $C D$ [mm] & $A D$ & $B C$ & $L$ [mm] & $W[\mathrm{~mm}]$ & $\bar{P}$ & $A$ & $F S F_{70 \%}$ \\
\hline NEC1 & 188.5 & 231.2 & 231.49 & 188.5 & 231.35 & 768.1 & 372.82 & 1.13 \\
\hline NEC5 & 176.39 & 241.82 & 241.79 & 176.39 & 241.81 & 714.47 & 336.3 & 1.1657 \\
\hline NEC2 & 178.89 & 241.9 & 241.9 & 178.89 & 241.9 & 718.78 & 322.56 & 1.1553 \\
\hline Belt1 & 192.23 & 244.75 & 244.75 & 192.23 & 244.75 & 735.23 & 325.9 & 1.1116 \\
\hline $\mathrm{NEC}^{9}$ & 181.82 & 242.41 & 242.38 & 181.82 & 242.4 & 722.36 & 314.17 & 1.143 \\
\hline Belt2 & 191.59 & 244.6 & 244.52 & 191.59 & 244.56 & 733.39 & 326.92 & 1.1124 \\
\hline NEC8 & 176.61 & 242.18 & 242.16 & 176.61 & 242.17 & 715.72 & 332.22 & 1.1604 \\
\hline Belt4 & 191.11 & 244.45 & 244.37 & 191.11 & 244.41 & 728.32 & 328.09 & 1.1136 \\
\hline NEC4 & 178.98 & 231.86 & 232.14 & 178.98 & 232 & 742.26 & 348.85 & 1.1584 \\
\hline $\mathrm{NEC}^{6}$ & 184.37 & 242.28 & 242.25 & 184.37 & 242.27 & 715.64 & 322.46 & 1.1388 \\
\hline Belt3 & 185.87 & 244.6 & 244.19 & 185.87 & 244.4 & 727.94 & 337.36 & 1.1296 \\
\hline NEC7 & 173.12 & 242.19 & 242.18 & 173.12 & 242.19 & 711.46 & 351.8 & 1.1756 \\
\hline Belt6 & 186.17 & 244.15 & 244.08 & 186.17 & 242.12 & 725.65 & 335.91 & 1.1306 \\
\hline $\mathrm{NEC}^{3}$ & 169.77 & 231.66 & 231.93 & 169.77 & 231.8 & 754.22 & 365.54 & 1.187 \\
\hline Belt 9 & 186.2 & 243.99 & 243.91 & 186.2 & 243.95 & 722.71 & 344.38 & 0.9673 \\
\hline Belt8 & 192.59 & 244.35 & 244.27 & 192.59 & 244.31 & 728.16 & 326.73 & 1.113 \\
\hline Belt7 & 192 & 244.32 & 244.24 & 192 & 244.28 & 723.12 & 329 & 1.1145 \\
\hline Belt5 & 192.39 & 244.46 & 244.38 & 192.39 & 244.42 & 721.37 & 327.76 & 1.1119 \\
\hline
\end{tabular}


to the lateral side of the sidewall, causing an increase in the sidewall vibration and noise.

4. The width of tire-ground does not have any correlation with the vibration noise.

5. With an increase in the ground shape factor $F S F_{70 \%}$, the vibration noise first fluctuates smoothly and then increases to an extremely high

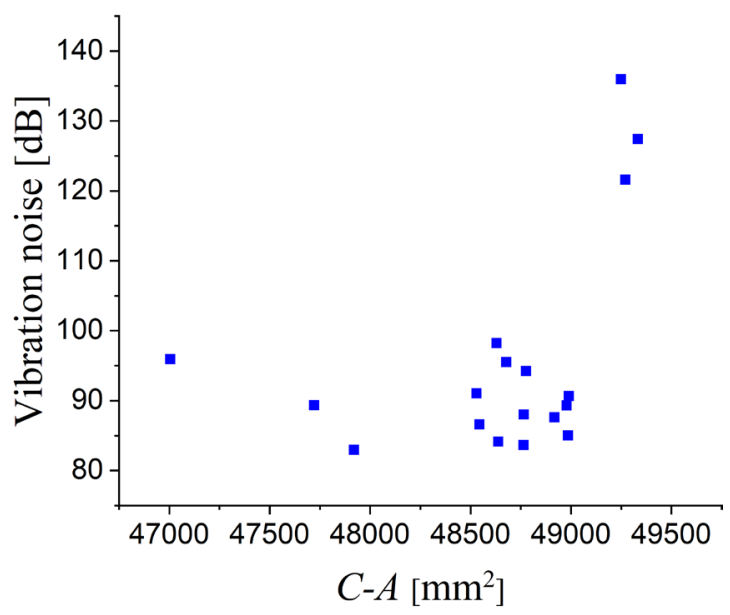

a)
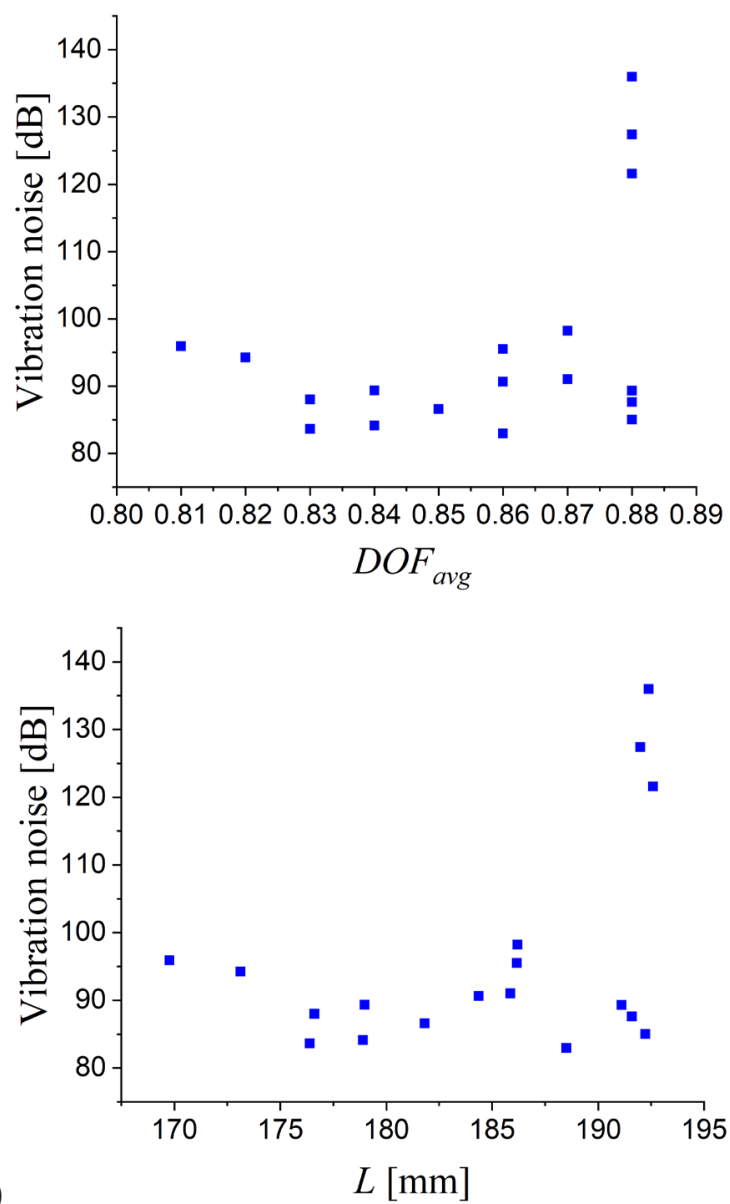

value when the ground shape factor is nearly 0.79. When the $F S F_{70 \%}$ tends to 1, the vibration noise increases; the smaller the third axis and the $D O F_{a v g}$ are, the greater the ground length and the $D O F_{\text {avg }}$ are, and the greater the vibration noise is.

6. With the increase in the average pressure and the pressure skewness, the vibration noise first
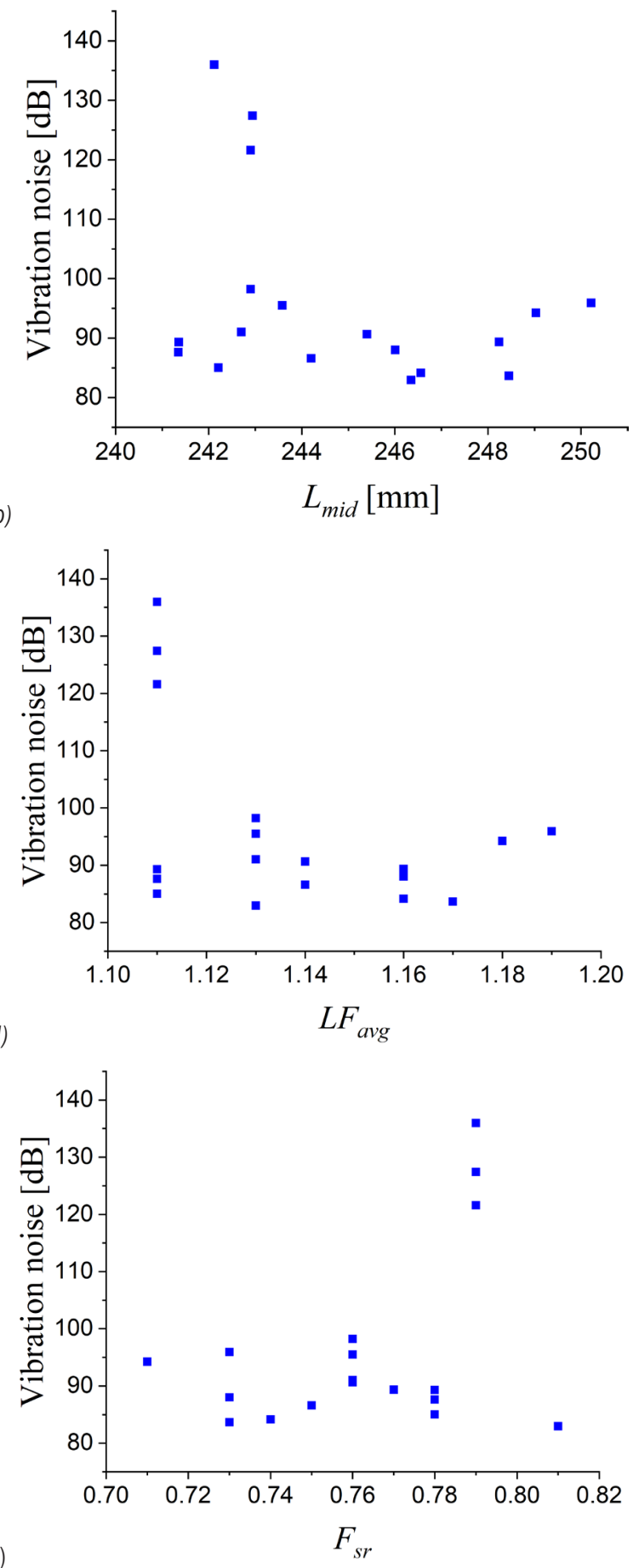

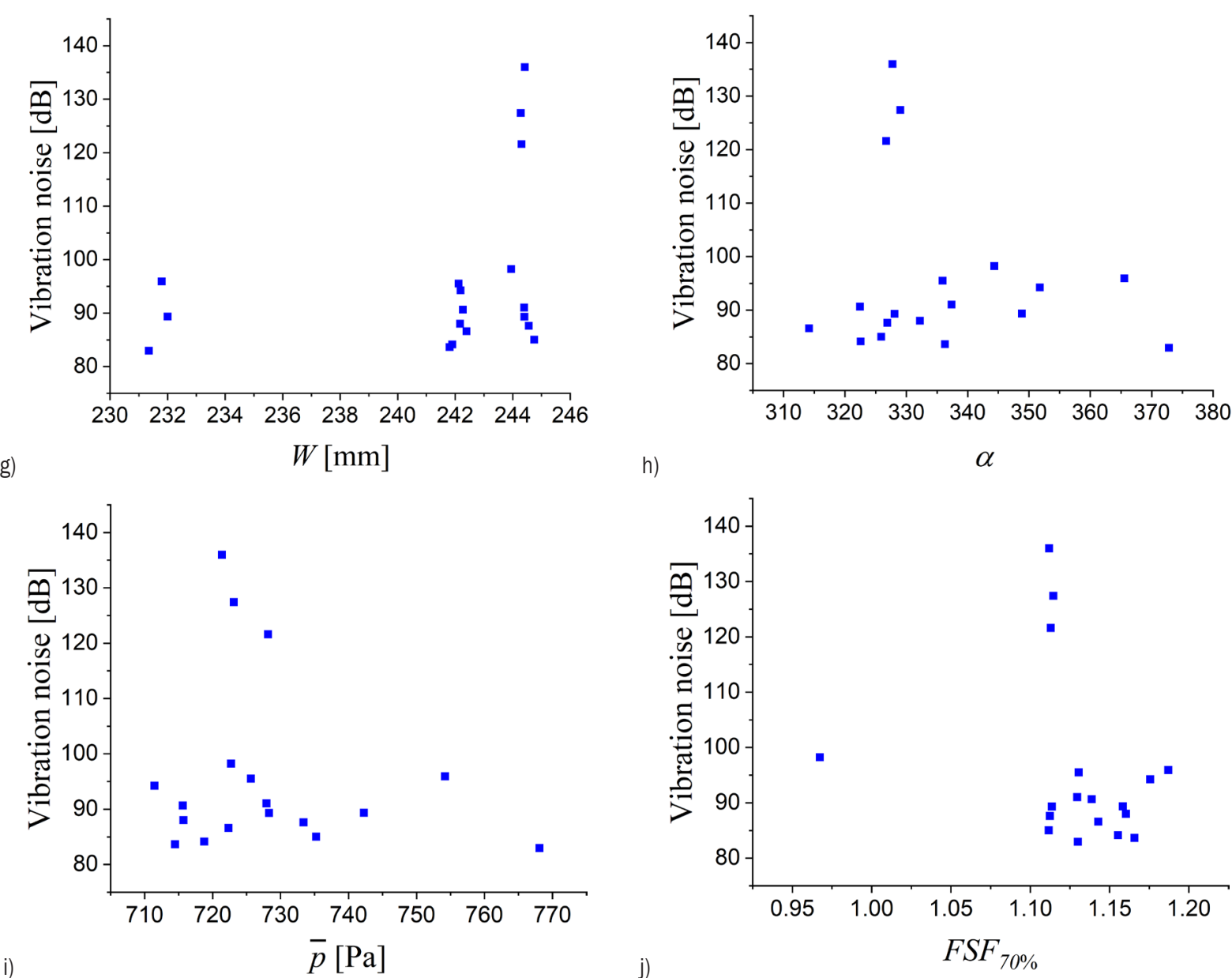

Fig. 13. Relationship between ground parameters and vibration noise; the relationship between vibration noise and a) $C-A$, b) $L_{m i d}$, c) $D O F_{a v g}$, d) $L F_{a v g}$, e) $L$, f) $L_{s r}$, g) $W$, h) $\alpha$, i) $\bar{P}$, and j) $F S F_{70 \%}$

increases, then decreases, and finally tends to smooth fluctuation; this implies that the average pressure and the pressure skewness should be controlled to a certain extent.

7. The vibration noise is greatly related to the ground shape factor, except for the ground shape factor 0.97, which may be a singular point of vibration noise; the vibration noise is mainly distributed around the shape factor with a range of 1.1 to 1.2. In this range, the noise first decreases and then increases.

\subsection{Relationship between Tread Deformation and Noise}

\subsubsection{Definition of Tread Deformation Parameters}

When a tire is rolling on a road, the tread radial deformation in the ground area is the main cause of tire vibration. Different tire structure designs will lead to different radial force distribution and different radial deformation in the contact area. In this study, the tread radial deformation skewness and stiffness are selected to study the effect of radial force distribution on vibration noise.

The degree of dispersion of the tread radial deformation profile when a tire is in contact with a road is characterized by the tread radial deformation skewness, which, to a certain extent, can reflect the continuity of the tread radial deformation. The formula for the skewness of the tread radial deformation is given in Eq. (4):

$$
S=\sqrt{\frac{1}{n-1} \sum_{i=1}^{n}\left(d_{z i}-\overline{d_{z}}\right)^{2}},
$$

where $n$ is the number of nodes in the contact area, $d_{z i}$ is the radial deformation of the $i^{\text {th }}$ node, and $\overline{d_{z}}$ is the average of the radial deformation of all nodes in the contact area. 
The radial deformation stiffness distribution of the tread is defined as shown in Eq. (5):

$$
k_{z}=\frac{f_{z}}{d_{z}}
$$

where $f_{z}$ is the ground pressure of the tread node in $[\mathrm{Pa}]$, and $d_{z}$ is the radial deformation of the tread node in $[\mathrm{m}]$.

The ground pressure and radial deformation of the tread nodes in a contact patch are calculated from the output of Abaqus Software, and the radial deformation stiffness profile of the tire is computed in Matlab Software.

\subsubsection{Effects of Tread Deformation of Contour Design on Noise}

Fig. 14 shows the radial deformation distribution using the non-natural equilibrium contour design with the minimum vibration noise. It can be seen that the radial deformation of the tread at the central area is large, the deformation at the surrounding areas is small, and it rapidly reduces from the central area to the surrounding area. The largest central deformation area is not continuous, which is caused by the longitudinal grooves; therefore, it leads to stress concentration phenomenon in the contact width y-direction. The maximum deformation in the contact area is 38.562 $\mathrm{mm}$, and the minimum deformation in the edges is $8.19 \mathrm{~mm}$ in the contact length $\mathrm{x}$-direction.

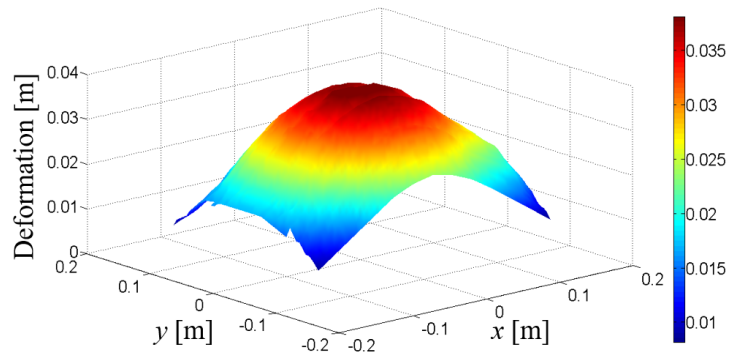

Fig. 14. Tire radial deformation distribution in the noise minimization using contour design

To further obtain ground parameters, the contact area is divided into five subareas: $C_{A}$ for the ground front, $C_{B}$ for the ground centre area, $C_{C}$ for the ground back, and $C_{D}$ and $C_{E}$ for the tread on both sides of the tire shoulder area, as shown in Fig. 15. The deformation stiffness in the five subareas is the average deformation stiffnesses of the tread nodes, which is calculated using Eq. (6).

$$
K_{\left(C_{A}, C_{B}, \ldots, C_{E}\right)}=\frac{\sum_{i=1}^{n} k_{z i}}{n} .
$$

Many studies [1] and [2] have shown that the vibration noise produced by the front and rear of a tire coming into contact with the ground is asymmetrical. Therefore, the above five subareas must be studied separately. In order to determine the principle of subareas division, the skewness of tread deformation is studied by changing the size of the five subareas. When the skewness of the each of subareas reaches a relative minimum, the subareas profile are fixed for partitioning the areas.

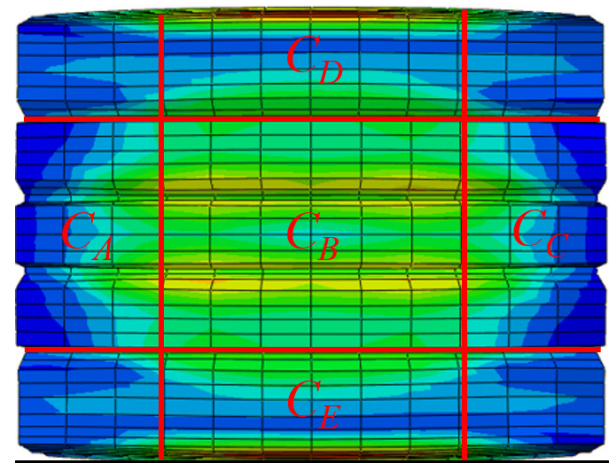

Fig. 15. Tire contact area division

Table 5. Tire radial deformation in the noise minimization design

\begin{tabular}{|c|c|c|c|c|c|c|}
\hline \multirow{2}{*}{$\begin{array}{l}\text { Minimum } \\
\text { noise }\end{array}$} & \multicolumn{5}{|c|}{ Tread radial deformation skewness $\times 10^{-3}$} & \multirow{2}{*}{$\begin{array}{c}\text { Noise } \\
{[\mathrm{dB}]}\end{array}$} \\
\hline & $C_{A}$ & $C_{B}$ & $C_{C}$ & $C_{D}$ & $C_{E}$ & \\
\hline $\begin{array}{l}\text { Structure } \\
\text { design }\end{array}$ & 5.3655 & 3.3903 & 5.3655 & 2.6793 & 2.6786 & 81.73 \\
\hline $\begin{array}{l}\text { Original } \\
\text { design }\end{array}$ & 5.4327 & 3.4428 & 5.4327 & 2.7678 & 2.7680 & 91.77 \\
\hline
\end{tabular}
and original design

The skewness of the tread radial deformation of the five subareas shown in Fig. 15 is studied and compared with the skewness of the tread radial deformation under the noise minimization contour design and the original structural design. The comparable results are listed in Table 5. As shown in the table, the skewness of the tread radial deformation of the two tires at the front and rear ends $\left(C_{A}\right.$ and $\left.C_{C}\right)$ and both sides of the tread $\left(C_{D}\right.$ and $\left.C_{E}\right)$ are similar and symmetrical. It is also observed that the skewness of the tread radial deformation at $C_{A}, C_{B}, C_{C}, C_{D}$, and $C_{E}$ of the tire with the original design is larger than that of the noise minimization contour design.

Fig. 16 shows the radial deformation stiffness of the noise minimization contour design and original design. It can be seen that the subarea $C_{B}$ of the two 
tires is relatively high, and that of the $C_{A}$ and $C_{C}$ regions are relatively low. Stress concentrates near the shoulder because of the stirrup effect of the belt layer. The concave part in Fig. 16 is caused by the discontinuity of the longitudinal grooves.

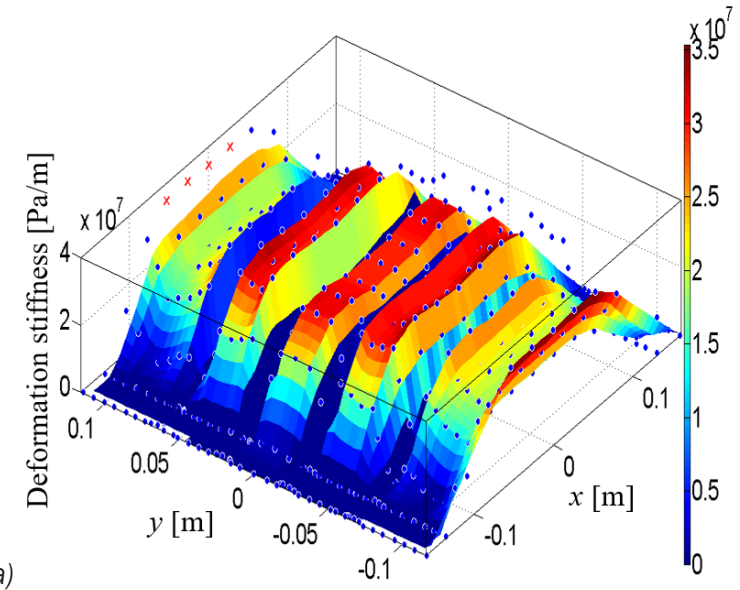

a)

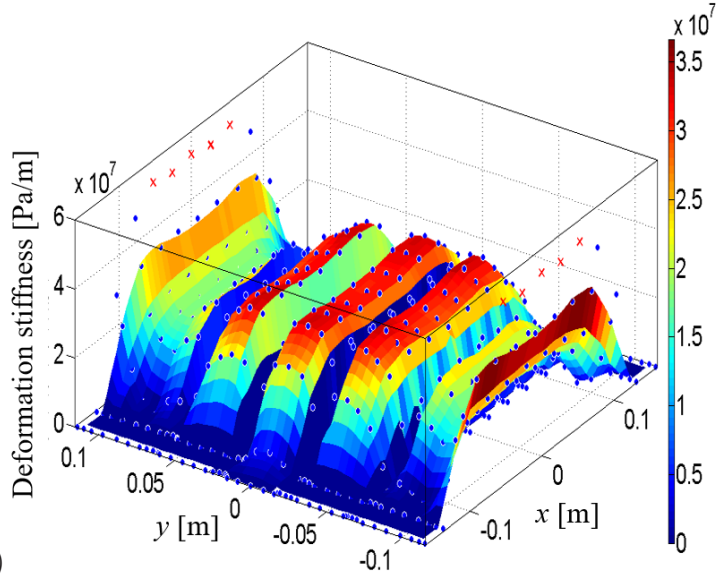

Fig. 16. Tire radial deformation stiffness in noise minimization using a) contour design; and b) original design

The average values of the radial deformation stiffness of the five subareas in the noise minimization design and original design are listed in Table 6, in which it can be seen that the tread radial deformation stiffness is the largest on both sides of the tread near the shoulder $\left(C_{D}\right.$ and $\left.C_{E}\right)$, followed by the tread centre area $\left(C_{B}\right)$. The radial deformation stiffness of the tread at $C_{A}$ and $C_{C}$ is the smallest. The radial deformation stiffnesses of the treads near the shoulder $\left(C_{D}\right.$ and $C_{E}$ ) are similar to each other, and so are the radial deformation stiffnesses at the front and rear $\left(C_{A}\right.$ and $C_{C}$ ); the distribution is symmetrical. By comparing the two tires, it is found that the tread radial deformation stiffness values at $C_{B}, C_{D}$, and $C_{E}$ are larger in the noise minimization design, whereas the radial deformation stiffness values of the tread at $C_{A}$ and $C_{C}$ in both designs are similar with small differences.

Table 6. Average values of tire radial deformation stiffness in noise minimization design and original design

\begin{tabular}{lcccccc}
\hline Minimum & \multicolumn{5}{c}{ Deformation stiffness $\left[\times 10^{6} \mathrm{~Pa} / \mathrm{m}\right]$} & Noise \\
\cline { 2 - 6 } noise & $C_{A}$ & $C_{B}$ & $C_{C}$ & $C_{D}$ & $C_{E}$ & [dB] \\
\hline $\begin{array}{l}\text { Structure } \\
\text { design }\end{array}$ & 5.8518 & 15.8462 & 5.8516 & 32.5315 & 32.5357 & 81.73 \\
\hline $\begin{array}{l}\text { Original } \\
\text { design }\end{array}$ & 5.6066 & 14.7364 & 5.6068 & 28.3505 & 28.3522 & 91.77 \\
\hline
\end{tabular}

\subsubsection{Effects of Tread Deformation of Belt Design on Noise}

Fig. 17 shows the radial deformation of the tread used in the noise minimization using belt design. As seen in the figure, the radial deformation of the tread at the central area is large, and the deformation in the surrounding areas is small, and it is radially reduced from the central area to surrounding area. Continuous deformation is not observed in the central area, which is caused by the longitudinal grooves. The maximum deformation in the contact area is $37.607 \mathrm{~mm}$, and the minimum deformation in the edges is $8.111 \mathrm{~mm}$.

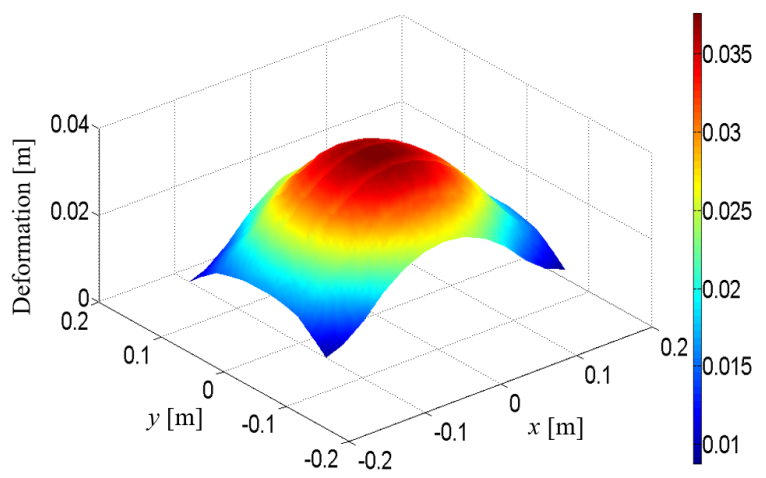

Fig. 17. Tire radial deformation distribution in noise minimization using belt design

The skewness of the tread radial deformation in the noise minimization belt design and original design is listed shown in Table 7. As seen in the table, the skewness values of the tread radial deformation of the two tires at the front and rear ends $\left(C_{A}\right.$ and $\left.C_{C}\right)$ are similar to each other and symmetrical, as are the skewness values on both sides of the tread $\left(C_{D}\right.$ and $\left.C_{E}\right)$. By comparing and analysing the skewness of the tread radial deformation of the two tires, it is found that the skewness values of the tread radial deformation at $C_{A}, C_{B}, C_{C}, C_{D}$, and $C_{E}$ in the original design are larger than that of the noise minimization belt structure design. 
Table 7. Standard deviation of tire radial deformation in noise minimization design and original design

\begin{tabular}{lcccccc}
\hline Minimum & \multicolumn{4}{c}{ Tread radial deformation skewness $\times 10^{-3}$} & Noise \\
\cline { 2 - 6 } noise & $C_{A}$ & $C_{B}$ & $C_{C}$ & $C_{D}$ & $C_{E}$ & {$[\mathrm{~dB}]$} \\
\hline $\begin{array}{l}\text { Structure } \\
\text { design }\end{array}$ & 5.2338 & 3.3412 & 5.2338 & 2.6755 & 2.6755 & 84.22 \\
\hline $\begin{array}{l}\text { Original } \\
\text { design }\end{array}$ & 5.4327 & 3.4428 & 5.4327 & 2.7678 & 2.7680 & 91.77 \\
\hline
\end{tabular}

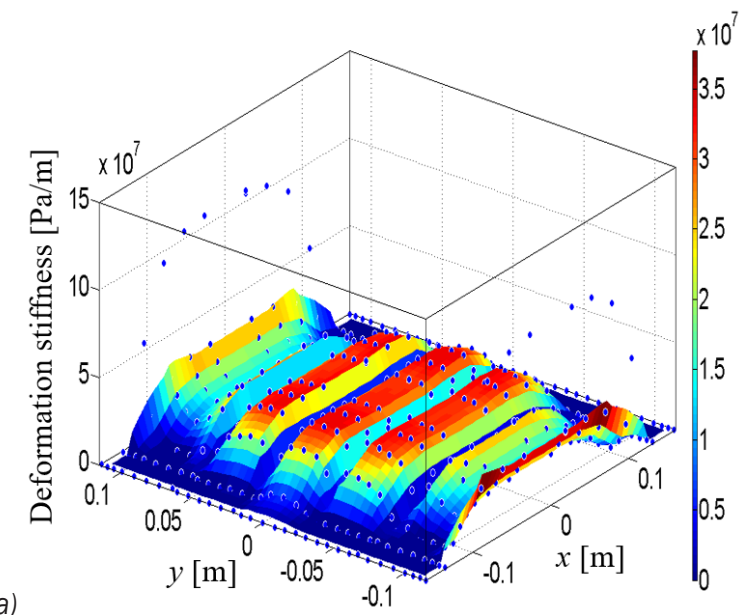

a)

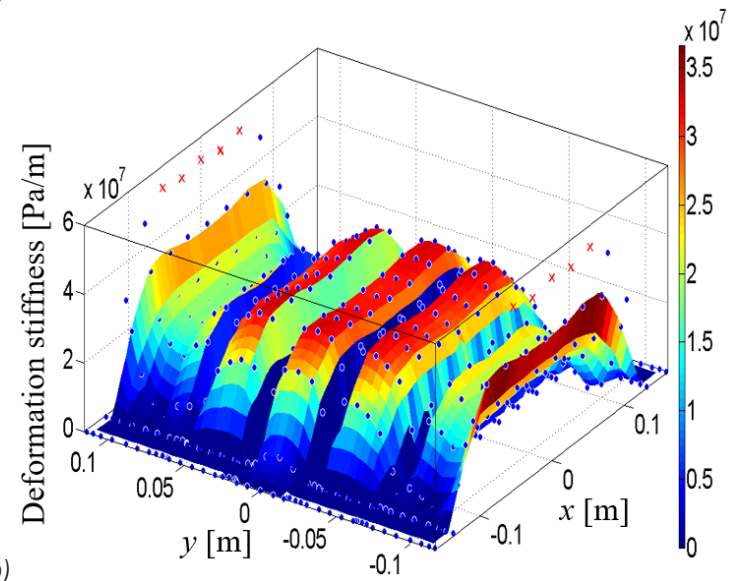

Fig. 18. Tire radial deformation stiffness in noise minimization: a) using belt design; and b) original design

The results of a comparative analysis of the radial deformation stiffness of the noise minimization belt structure design and the original design are shown in Fig. 18. As shown in the figure, the radial deformation stiffness of the tread at the center $\left(C_{B}\right)$ in the two tires is relatively high, whereas that at $C_{A}$ and $C_{C}$ is relatively low. The concave part of the Fig 18 is caused by the longitudinal grooves of the tire.

The average values of tire radial deformation stiffness of five subareas in the noise minimization belt structure design and original design are listed in Table 8. As listed in Table 8, the tread radial deformation stiffness is the largest on both sides of the tread $\left(C_{D}\right.$ and $\left.C_{E}\right)$, followed by the tread centre area $\left(C_{B}\right)$. The radial deformation stiffness of the tread at $C_{A}$ and $C_{C}$ is the smallest. The radial deformation stiffness of the tread near the shoulder $\left(C_{D}\right.$ and $\left.C_{E}\right)$ are similar, as are the radial deformation stiffness at the front and rear $\left(C_{A}\right.$ and $\left.C_{C}\right)$; the distribution is symmetrical. By comparing the two tires, it is found that the tread radial deformation stiffness at $C_{A}, C_{B}$, $C_{C}, C_{D}$, and $C_{E}$ are higher in the noise minimization belt structure design.

\subsection{Relationship between Tire Radial Excitation Force and Noise}

In the signal spectrum analysis, the power spectral density is not only reflecting the signal energy change in frequency range but also reflects the vibration energy [28]. Therefore, the causes of minimum tire vibration noise reduction can be analysed from the power spectral density of the tire radial force excitation.

Fig. 19 shows the tire excitation power spectral density of the noise minimization design using the new non-natural equilibrium contour design and that of the original design. It can be seen that the peak value and number of the power spectral density in the noise minimization are less compared with the original design, especially in $50 \mathrm{~Hz}$ to $130 \mathrm{~Hz}, 220 \mathrm{~Hz}$ to $340 \mathrm{~Hz}$, and $440 \mathrm{~Hz}$ to $500 \mathrm{~Hz}$ frequency ranges. At the same time, considering the noise spectrum characteristics showed in Fig.10, it can been that, the spectral density is low at the sensitive frequencies of $440 \mathrm{~Hz}$ and $488 \mathrm{~Hz}$, and the reduction in tire vibration noise is due to the reduction in the energy of tire radial excitation force.

Fig. 20 shows the tire excitation power spectral density the noise minimization design using the belt

Table 8. Average values of tire radial deformation stiffness in the noise minimization design and original design

\begin{tabular}{lcccccc}
\hline \multirow{2}{*}{ Minimum noise } & \multicolumn{5}{c}{ Deformation stiffness $\times 10^{6}$} & $C_{E}$ \\
\cline { 2 - 6 } & $C_{A}$ & $C_{B}$ & $C_{C}$ & $C_{D}$ & Noise [dB] \\
\hline Structure design & 8.6286 & 22.1175 & 8.3738 & 37.3629 & 37.3629 & 81.73 \\
\hline Original design & 5.6066 & 14.7364 & 5.6068 & 28.3505 & 28.3522 & 91.77 \\
\hline
\end{tabular}


design and that of the original design. As shown in the figure, the peak value of the exciting power spectrum density of the noise minimization design using the belt optimization reduces remarkably. Combining the sound pressure frequency-response function of Fig. 10 , it shows that the belt optimization design could result in a minimum excitation power spectral density compared with the original design, and the impacts of the $220 \mathrm{~Hz}$ to $260 \mathrm{~Hz}$ and $380 \mathrm{~Hz}$ to $450 \mathrm{~Hz}$ frequency ranges of the power spectrum are significantly reduced. In particular, at the sensitive frequency of $440 \mathrm{~Hz}$, the power density of the tire radial force excitation decreases.

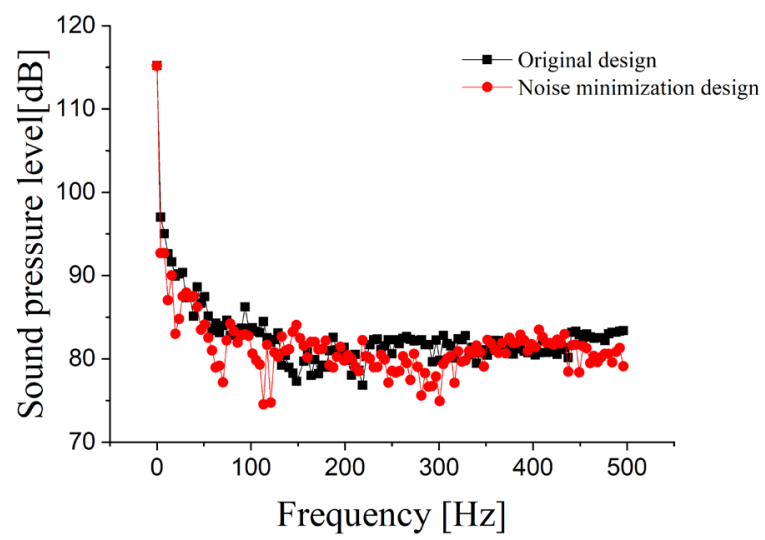

Fig. 19. Comparison of power spectral density in the noise minimization contour design and original design

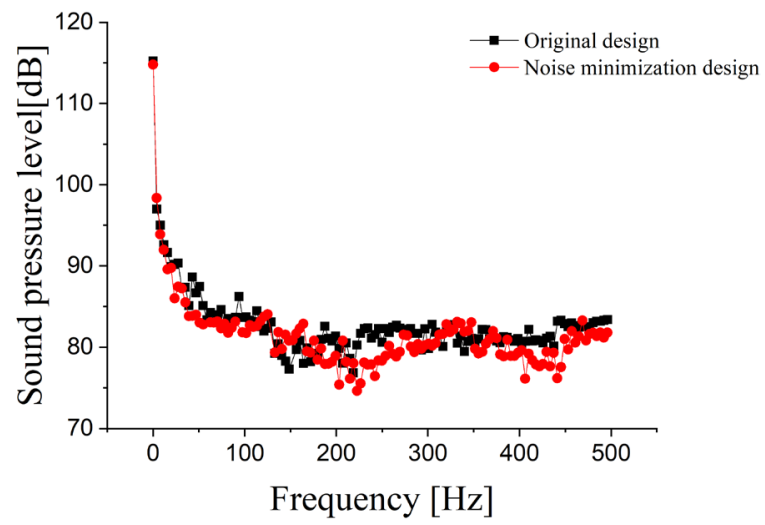

Fig. 20. Comparison of power spectral density in the noise minimization belt design and original design

\section{CONCLUSIONS}

1. Numerical simulations are conducted to establish a tire model and analyse tire vibration noise. The results of the tire modal and noise of different tire structures designed using the orthogonal experimental design method showed that the structural design of a tire had only a slight impact on the tire's natural frequency but a considerable impact on vibration noise.

2. This study introduced a series of geometric and mechanical parameters to describe the tire ground characteristics, and the relationship between ground characteristics and vibration noise is established. Reduction in the coefficient of the third-longest axis $L F_{\text {avg }}$ and increase in the coefficient of the second-longest axis $D O F_{\text {avg }}$ would enhance tire vibration noise; there is no significant relationship between contact width $W$ and tire vibration noise; the value of the shape coefficient of the tire-ground $F_{s r}$ being close to 1 means the large tire vibration noise.

3. The tire contact patch is divided into five subareas, and the skewness and stiffness of the radial deformation of the tread at these five subareas are analysed; the results showed that the skewness had a positive correlation with tire vibration noise (i.e., the smaller the skewness of the tread radial deformation is, the lower the vibration noise is). The radial deformation stiffness of the tread had a negative correlation with the tire vibration noise (i.e., tire vibration noise increased as the tread deformation stiffness decreased).

4. The power spectral density is selected to describe the impact force response of the rolling tire in contact with the road. A comparison between the power spectral density of the noise minimization design and that of the original design, the results showed that the peak value and quantity of power spectral density of the noise minimum structure design decreased significantly, especially at the sensitive frequencies of $440 \mathrm{~Hz}$ and $488 \mathrm{~Hz}$. It infers that a decreasing tire radial impact reduces the tire vibration noise.

\section{ACKNOWLEDGEMENTS}

This work is supported by the National Natural Science Foundation of China under Grant 52072156 and 51675240 .

\section{REFERENCES}

[1] Sandberg, U., Ejsmont, J.A. (2002). Tyre/Road Noise Reference Book. INFORMEX, Kisa.

[2] Li, T. (2018). Literature review of tire-pavement interaction noise and reduction approaches. Journal of Vibroengineering, vol. 20, no. 6, p. 2424-2452, D0l:10.21595/jve.2018.19935.

[3] Diaz, C.G., Kindt, P., Middelberg, J., Vercammen, S., Thiry, C., Close, R., Leyssens, J. (2016). Dynamic behaviour of a 
rolling tyre: Experimental and numerical analyses. Journal of Sound and Vibration, vol. 364, p. 147-164, D0I:10.1016/j. jsv.2015.11.025.

[4] Del Pizzo, A., Teti, L., Moro, A., Bianco, F., Fredianelli, L., Licitra, G. (2020). Influence of texture on tyre road noise spectra in rubberized pavements. Applied Acoustics, vol. 159, p. 1-12, DOI:10.1016/j.apacoust.2019.107080.

[5] Keltie, R.F. (1982). Analytical model of the truck tire vibration sound mechanism. The Journal of the Acoustical Society of America, vol. 71, no. 2, p. 359-367, Dol:10.1121/1.387460.

[6] Belgacem, W., Berry, A., Masson, P. (2012). Active vibration control on a quarter-car forconcellation of road noise distribution. Journal of Sound and Vibration, vol. 331, no. 14, p. 3240-3254, DOI:10.1016/j.jsv.2012.02.030.

[7] Dubois, G., Cesbron, J., Yin, H.P., Anfosso-Lédée, F., Duhamel, D. (2013). Statistical estimation of low frequency tyre/road noise from numerical contact forces. Applied Acoustics, vol. 74, no. 9, p. 1085-1093, D0l:10.1016/J.apacoust.2013.03.011.

[8] Zhou, H., Wang, G., Zhang, Y., Yang, J., Zheng, Z. (2017). Study of the influence of tire belt structure on vibration noise. Recent Patents on Mechanical Engineering, vol. 10, no. 4, p. 270-278, D0I:10.2174/2212797610666170817095107.

[9] Wang, G.L., Pei, X.P., Zhou, H.C., Zhao, F., Yang, J. (2015). Acoustic contribution of tire structure vibration and method for noise reduction. Journal of Vibration and Shock, no. 24, p. 5358, D0l:10.13465/j.cnki.jvs.2015.24.009. (in Chinese)

[10] Zhang, Z., Fu, H., Liang, X., Chen, X., Tan, D. (2020). Comparative analysis of static and dynamic performance of nonpneumatic tire with flexible spoke structure. Strojniški vestnik - Journal of Mechanical Engineering, vol. 66, no. 6-7, p. 458-466, Dol:10.5545/sv-jme.2020.6676.

[11] Wang, G.L., Qian, H., Zhou, H.C., Qiao, L., Liu, C.Z. (2019). Relationship between the tire hydroplaning speed and noise performance based on grounding characteristics. Journal of Jilin University (Engineering and Technology Edition), vol. 49, no. 1, p. 14-23, D0l:10.13229/j.cnki.jdxbgxb20171057. (in Chinese)

[12] Li, T. (2018). Influencing parameters on tire-pavement interaction noise: Review, experiments, and design considerations. Designs, vol. 2, no. 4, p. 1-38, D0l:10.3390/ designs2040038.

[13] Du, X., Zhao, Y., Wang, Q., Fu, H., Lin, F. (2019). Grounding characteristics of a non-pneumatic mechanical elastic tire in a rolling state with a camber angle. Strojniški vestnik Journal of Mechanical Engineering, vol. 65, no. 5, p. 287-296, DOl:10.5545/sv-jme.2018.5845.

[14] Wang, G.L., Zhang, P., Zhou, H.C., Yang, J., Zheng, Z., Ren, X.J. (2017). Effect of tread deformation and stiffness on road holding performance. Journal of Mechanical Engineering, vol. 53, no, 10, p. 108-115, D0l:10.3901/JME.2017.10.108. (in Chinese)

[15] Liang, C., Zhao, F., Wang, G.L., Yang, J., Zhou, H.C., Wang, Z.J. (2015). Tire vibration noise study of radial truck tire based on a new non-natural equilibrium design. Journal of Vibration
Engineering, vol. 28, no. 5, p. 800-808, D0l:10.16385/j.cnki. issn.1004-4523.2015.05.016.

[16] Hubbell, D.R. Jr. (2001). EP0944484B1. Method for Characterizing Noise Level of Rotating Tire. European Patent Office, Munich.

[17] Cesbron, J., Anfosso-Lédé, F., Duhamel, D., Yin, H. P., Le Houédec, D. (2009). Experimental study of tyre/road contact forces in rolling conditions for noise prediction. Journal of Sound and Vibration, vol. 320, no. 1-2, p. 125-144, D0l:10.1016/j.jsv.2008.07.018.

[18] Cohn, A. (2015). Commercial trailer tires: Tire inflation and its effect on rolling resistance, fuel economy, and tire footprint. Tire Science and Technology, vol. 43, no. 2, p. 144-162, DOl:10.2346/tire.15.430201.

[19] Zhou, H., Wang, G., Ding, Y., Yang, J., Liang, C., Fu, J. (2015). Effect of friction model and tire maneuvering on tire-pavement contact stress. Advances in Materials Science \& Engineering, vol. 2015, p. 1-11, D0l:10.1155/2015/632647.

[20] Wei, Y., Feng, X., Fuqiang, Z., Xiang, D. (2016). Simulation of rolling noise based on the mixed Lagrangian-Eulerian method. Tire Science and Technology, vol. 44, no. 1, p. 36-50, Dol:10.2346/tire.16.440103.

[21] Citarella, R., Federico, L., Cicatiello, A. (2007). Modal acoustic transfer vector approach in a FEM-BEM vibro-acoustic analysis. Engineering Analysis with Boundary Elements, vol. 31, no. 3, p. 248-258, D0l:10.1016/j.enganabound.2006.09.004.

[22] Iwao, K., Yamazaki, I. (1996). A study on the mechanism of tire/road noise. JSAE Review, vol. 17, no. 2, p. 139-144, DOI:10.1016/0389-4304(95)00004-6.

[23] Liu, Z.C., Ming, L., Li, J., Fang, Y., Dong, M.H. (2011). Effect of belt structure on footprint,radial stiffness and noise of PCR tire. Tire Industry, vol. 31, no. 9, p. 534-536, D0l:10.3969/j. issn.1006-8171.2011.09.004.

[24] Sakai, E.H. (1995). Measurement and visualization of the contact pressure distribution of rubber disks and tires. Tire Science and Technology, vol. 23, p. 238-255, DOI:10.2346/1.2137506.

[25] Yang, J., Wang, G.L., Wang, Z.J. (2015). A study on the new Non-natural equilibrium contour design of vehicle tires with conflicting performance compatibility. Automotive Engineering, vol. 37, no. 12, p. 1418-1425, D0l:10.3969/j. issn.1000-680X.2015.12.011. (in Chinese)

[26] Wang, Y.Q., Huo, X.W. (2018). Multi-objective optimization design and performance prediction of centrifugal pump based on orthogonal test. Advances in Materials Science and Engineering, vol. 2018, p. 1-10, D0l:10.1155/2018/6218178.

[27] Wang, G.L., Qiao, L., Zhou, H.C., Qiao, H., Liu, C.Z. (2019). Influence of PCR tire grounding characteristics to noise and rolling resistance. Journal of Mechanical Engineering, vol. 55, no. 16, p. 123-131, Dol:10.3901/JME.2019.16.123. (in Chinese)

[28] Múčka, P., Stein, G.J., Tobolka, P. (2020). Whole-body vibration and vertical road profile displacement power spectral density. Vehicle System Dynamics, vol. 58, no. 4, p. 630-656, D0I:10.1 080/00423114.2019.1595675. 